\title{
THE IMPACT OF BIG DATA ON M\&S: DO WE NEED TO GET “BIG”?
}

\author{
Simon J. E. Taylor \\ Brunel University London \\ St. Johns Building \\ Kingston Lane \\ London, UB8 3PH, UK
}

\begin{abstract}
Driven by innovations such as mass customisation, complex supply chains, smart cities and emerging cyber-physical and Internet of Things systems, Big Data is presenting a fascinating range of challenges to Analytics. New fields are emerging such as Big Data Analytics and Data Science. Modeling \& Simulation $(\mathrm{M} \& S)$ is core to Analytics. Arguably, contemporary M\&S practices cannot deal with the demands of Big Data. The implication of this is that M\&S may not feature in the Big Data Analytics techniques and tools of the future. Based on recent experiences from the i4MS FP7 European Cloudbased Simulation platform for Manufacturing and Engineering (CloudSME) and associated industrial projects, this talk will outline the key challenges that Big Data has to M\&S and strongly argue that M\&S has to get "Big" to meet these challenges. Exciting opportunities lie ahead for multi-disciplinary teams of practitioners and researchers from OR/MS, Computer Science and domain specific fields. Indeed "Big" Simulation presents its own possibilities and the talk will conclude with thoughts on the potential for "Big" Simulation Analytics to move beyond Big Data into future Dynamic Data Driven Application Systems.
\end{abstract}

\section{AUTHOR BIOGRAPHY}

SIMON TAYLOR is the leader of the Modelling \& Simulation Group and a Reader in the Department of Computer Science and the Health Economics Research Group at Brunel University London. He has worked in modelling \& simulation and high performance computing for over 20 years and has applied the outcomes of this research through collaborations of academic and industrial stakeholders both nationally and internationally that have led to over $£ 1$ million in productivity increases in the UK alone and have enabled a new generation of decision support systems and techniques in manufacturing, energy and defence industries. He has also led projects in healthcare that use modelling \& simulation techniques to investigate healthcare intervention strategies and effective clinical pathways and a range of projects realizing e-Science in Africa that leverage the on-going EU AfricaConnect Initiative. In addition to cofounding the Journal of Simulation he is the Editor of the OR Essential Book Series (ORS/Palgrave Macmillan), a member of the ACM SIGSIM Steering Committee and an active member of the UK OR Society. 